Article

\title{
Chemical Composition and Toxicity against Sitophilus zeamais and Tribolium castaneum of the Essential Oil of Murraya exotica Aerial Parts
}

\author{
Wei Qing Li ${ }^{1,2}$, Cai Hong Jiang ${ }^{3}$, Sha Sha Chu ${ }^{3}$, Ming Xue Zuo ${ }^{1}$ and Zhi Long Liu ${ }^{3, *}$
}

1 College of Life Sciences, Beijing Normal University, Haidian District, Beijing 100875, China;

E-Mails: liweiqing0102@sina.com (W.Q.L); mxzuo@bnu.edu.cn (M.X.Z.)

2 College of Chemical and Biological Engineering, Changsha University of Science and Technology, Changsha 41004, China

3 Department of Entomology, China Agricultural University, Haidian District, Beijing 100094, China; E-Mails: jiangcaihong1987@163.com (C.H.J.); chushasha3421@126.com (S.S.C.)

* Author to whom correspondence should be addressed; E-Mail: zhilongliu@cau.edu.cn; Tel.: +86-10-62732800; Fax: +86-10-62732800.

Received: 10 June 2010; in revised form: 17 August 2010 / Accepted: 19 August 2010 / Published: 25 August 2010

\begin{abstract}
In our screening program for new agrochemicals from Chinese medicinal herbs, Murraya exotica was found to possess insecticidal activity against the maize weevil, Sitophilus zeamais and red flour beetle, Tribolium castaneum. The essential oil of aerial parts of M. exotica was obtained by hydrodistillation and investigated by GC and GC-MS. The main components of $M$. exotica essential oil were spathulenol (17.7\%), $\alpha$-pinene (13.3\%), caryophyllene oxide (8.6\%), and $\alpha$-caryophyllene (7.3\%). Essential oil of $M$. exotica possessed fumigant toxicity against $S$. zeamais and $T$. castaneum adults with $\mathrm{LC}_{50}$ values of 8.29 and $6.84 \mathrm{mg} / \mathrm{L}$, respectively. The essential oils also show contact toxicity against $S$. zeamais and $T$. castaneum adults with $\mathrm{LD}_{50}$ values of 11.41 and $20.94 \mu \mathrm{g} / \mathrm{adult}$, respectively.
\end{abstract}

Keywords: Murraya exotica; Sitophilus zeamais; Tribolium castaneum; fumigant; contact toxicity; essential oil 


\section{Introduction}

Sitophilus and Tribolium species are two of the major pests of stored grains and grain products in the tropics and subtropics [1]. Control of stored product insects relies heavily on the use of synthetic insecticides and fumigants, which has led to problems such as environmental disturbances, increasing costs of application, pest resurgence, pest resistance to pesticides and lethal effects on non-target organisms, in addition to direct toxicity to users [2]. Fumigation plays a very important role in insect pest elimination in stored products [3]. Plant essential oils and their components have been shown to possess potential for development as new fumigants and they may have advantages over conventional fumigants in terms of low mammalian toxicity, rapid degradation and local availability [4]. Essential oils derived from more than 75 plant species have been evaluated for fumigant toxicity against stored product insects so far [5].

Botanical pesticides have the advantage of providing novel modes of action against insects that can reduce the risk of cross-resistance as well as offering new leads for design of target-specific molecules [2,6]. During our screening program for new agrochemicals from local wild plants and Chinese medicinal herbs, the essential oil from aerial parts of Murraya exotica L. have been found to possess insecticidal activity towards the maize weevil, Sitophilus zeamais (Motsch) and red flour beetle, Tribolium castaneum Herbst.

Murraya exotica belongs to the family Rutaceae and is an evergreen shrub or occasionally a small tree, usually 2 to $3 \mathrm{~m}$ in height but reaching $8 \mathrm{~m}$ and $13 \mathrm{~cm}$ in stem diameter. Its flowers are few, white, and very fragrant [7]. It is commonly cultivated in gardens in many tropical and subtropical countries for its glossy green foliage and large clusters of fragrant flowers [7]. An infusion of the leaves and flowers of $M$. exotica is tonic and stomachic. It is said to be aromatic, refrigerant, digestive, and beneficial in rheumatic fever, coughs, giddiness, hysteria, thirst, and burning of the skin [8,9]. Phytochemical studies on $M$. exotica revealed the presence of flavonoids, coumarins, phytosterols, alkaloids and volatile oil [10-25]. The chemical composition of essential oil of $M$. exotica has been widely studied [26-31]. The acetone extract of $M$. exotica leaves showed antifeedant activity against the $3^{\text {rd }}$ larvae of Spodptera litura [32] while the ethanol extract of this plant was found to possess antifeedant activity against aphids (Myzus persicae and Lipaphis erysimi) [33]. Moreover, murraxocin (coumarin), derived from M. exotica showed insecticidal activity against three important forest insect pests (Plecoptera reflexa, Clostera cupreata and Crypsiptya coclesalis). However, no report on insecticidal activity of essential oil of $M$. exotica against stored product insects was available.

\section{Results and Discussion}

\subsection{Chemical composition of the essential oil}

A total of 36 components were identified in the essential oil of $M$. exotica, accounting for $99.5 \%$ of the total oil). The chemical composition of the essential oil is shown in Table 1. The main constituents of the oil were spathulenol (17.7\%), $\alpha$-pinene (13.3\%), caryophyllene oxide $(8.6 \%), \alpha$-caryophyllene (7.3\%), and bicyclogermacrene (7.1\%), followed by 1,2,3,5,6,7,8,8a-octahydro-1-methyl-6-methylene4-(1-methylethyl)-naphthalene (6.5\%) and $\gamma$-selinene $(5.3 \%)$. 
Table 1. Chemical composition of the essential oil of Murraya exotica.

\begin{tabular}{|c|c|c|}
\hline Compounds & RI * & Relative content (\%) \\
\hline$\alpha$-Pinene & 931 & 13.2 \\
\hline$\alpha$-Phellandrene & 1005 & 0.2 \\
\hline$\delta$-3-Carene & 1010 & 0.5 \\
\hline$\rho$-Cymene & 1024 & 1.1 \\
\hline Linalool & 1094 & 0.5 \\
\hline$\alpha$-Terpineol & 1191 & 0.7 \\
\hline Thymol methyl ether & 1225 & 0.2 \\
\hline p-Menth-1(7)-en-2-one & 1238 & 0.3 \\
\hline Phellandral & 1281 & 0.8 \\
\hline Bornyl acetate & 1285 & 1.8 \\
\hline Thymol & 1292 & 2.2 \\
\hline 4-Vinylguaiacol & 1311 & 0.3 \\
\hline Eugenol & 1356 & 1.2 \\
\hline$\alpha$-Copaene & 1374 & 1.7 \\
\hline$\beta$-Patchoulene & 1388 & 1.0 \\
\hline$\beta$-Elemene & 1391 & 0.9 \\
\hline $\begin{array}{l}\text { 1,2,3,5,6,7,8,8a-octahydro-1-methyl-6- } \\
\text { methylene-4-(1-methylethyl)-Naphthalene }\end{array}$ & 1401 & 6.5 \\
\hline Caryophyllene & 1420 & 4.5 \\
\hline Calarene & 1432 & 0.7 \\
\hline$\alpha$-Caryophyllene & 1454 & 7.3 \\
\hline$\gamma$-Selinene & 1455 & 5.3 \\
\hline allo-Aromadendrene & 1458 & 0.2 \\
\hline$\gamma$-Muurolene & 1473 & 0.7 \\
\hline$\beta$-Selinene & 1475 & 1.5 \\
\hline$\alpha$-Amorphene & 1479 & 0.5 \\
\hline Germacrene D & 1481 & 0.8 \\
\hline Bicyclogermacrene & 1499 & 7.1 \\
\hline $1 \xi, 6 \xi, 7 \xi$-Cadina-4,9-diene & 1502 & 0.9 \\
\hline$\delta$-Cadinene & 1523 & 4.4 \\
\hline Cadina-1,4-diene & 1533 & 0.5 \\
\hline Eudesma-3,7(11)-diene & 1536 & 0.2 \\
\hline$\alpha$-Calacorene & 1543 & 0.7 \\
\hline cis-Nerolidol & 1535 & 1.2 \\
\hline Spathulenol & 1578 & 17.7 \\
\hline Caryophyllene oxide & 1583 & 8.6 \\
\hline$\alpha$-Cadinol & 1640 & 3.6 \\
\hline \multicolumn{2}{|r|}{ Total } & 99.5 \\
\hline
\end{tabular}

* RI, retention index as determined on a HP-5MS column using the homologous series of $n$ hydrocarbons.

Table 2. Insecticidal activity of the essential oil of Murraya exotica against Sitophilus zeamais (SZ) and Tribolium castaneum (TC) adults.

\begin{tabular}{|c|c|c|c|c|c|}
\hline \multirow[b]{2}{*}{ Insects } & \multirow[b]{2}{*}{ Essential oil } & \multicolumn{2}{|c|}{ Contact toxicity (7 d) } & \multicolumn{2}{|c|}{ Fumigant toxicity (7 d) } \\
\hline & & $\begin{array}{c}\mathbf{L D}_{50} \\
\text { ( } \mu \text { g/adult) }\end{array}$ & $\begin{array}{l}\text { 95\% confidence } \\
\text { limits }\end{array}$ & $\begin{array}{c}\mathrm{LC}_{50} \\
(\mathrm{mg} / \mathrm{L})\end{array}$ & $\begin{array}{l}\text { 95\% confidence } \\
\text { limits }\end{array}$ \\
\hline $\mathrm{SZ}$ & $\begin{array}{l}\text { M. paniculata } \\
\text { Pyrethrum extract } \\
\mathrm{MeBr}\end{array}$ & $\begin{array}{c}11.41 \\
4.29 \\
-\end{array}$ & $\begin{array}{c}10.77-12.12 \\
3.86-4.72 \\
-\end{array}$ & $\begin{array}{c}8.29 \\
- \\
0.67 *\end{array}$ & $\begin{array}{c}7.49-9.23 \\
- \\
-\end{array}$ \\
\hline $\mathrm{TC}$ & $\begin{array}{l}\text { M. paniculata } \\
\text { Pyrethrum extract } \\
\mathrm{MeBr}\end{array}$ & $\begin{array}{c}20.94 \\
0.36 \\
-\end{array}$ & $\begin{array}{c}19.62-22.53 \\
0.32-0.41 \\
-\end{array}$ & $\begin{array}{c}6.84 \\
- \\
1.75^{*}\end{array}$ & $\begin{array}{c}6.15-7.52 \\
- \\
-\end{array}$ \\
\hline
\end{tabular}

* data from Liu and Ho [1]. 
The results were quite different from the previous reports. These differences might have been due to harvest time and local, climatic and seasonal factors, as well as duration of the storage of the medicinal herbs. For example, the major constituents of volatile oil collected from Guangxi Autonomous District were bicyclogemacrene $(26.0 \%), \beta$-caryophyllene $(20.8 \%), \alpha$-caryophyllene $(5.8 \%), \delta$-cadinene (4.7\%), and spathulenol (4.3\%) [26]. Rina et al. [28] determined the chemical composition of essential oil of M. exotica leaves and flowers collected from India. The results indicated that the leaf oil showed $(E)$-nerolidol (27.8\%), $\alpha$-zingiberene $(10.0 \%), \beta$-caryophyllene $(9.7 \%),(E, E)$-farnesol $(8.9 \%)$ and $\delta$ elemene $(5.1 \%)$ as the major constituents, while the flower oil showed $(E, E, E)$ - $\alpha$-springene $(23.8 \%)$, (E)-nerolidol (18.7\%), (E,E)- $\alpha$-farnesene (13.2\%), methyl palmitate $(6.8 \%)$ and germacrene B (5.9\%) as the major constituents. However, the essential oil of $M$. exotica harvested from Cuba possessed $\beta$ caryophyllene (24.1\%) as major constituent [29] while Olawore et al. [30] found that the principal constituents of the leaf essential oil of $M$. exotica grown in Nigeria were $\beta$-cyclocitral $(22.9 \%)$, methyl salicylate $(22.4 \%)$, and trans-nerolidol $(11.7 \%)$, while the most abundant constituent of the fruit essential oil was $\beta$-caryophyllene (43.4\%) followed by (-)-zingiberene (18.9\%) and germacrene D $(8.3 \%)$. However, the essential oils of fresh flowers, leaves and fruits of $M$. exotica cultivated in Egypt possessed a major component, $\alpha$-pinene $(88.9 \%, 62.5 \%$, and $80.4 \%$, respectively [31]. Further studies on plant cultivation and essential oil standardization are needed because chemical composition of the essential oil varies greatly with the plant population.

\subsection{Insecticidal activity}

The essential oil of $M$. exotica showed contact toxicity against $S$. zeamais and $T$. castaneum adults with $\mathrm{LD}_{50}$ values of 11.41 and $20.94 \mu \mathrm{g}$ /adult, respectively (Table 2). Compared with the famous botanical insecticide, pyrethrum extract, the essential oil was 2.5 times less active against the maize weevils and 58 times less active against the red flour beetles because pyrethrum extract displayed $\mathrm{LD}_{50}$ value of 4.29 and $0.36 \mu \mathrm{g}$ /adult, respectively (Table 2). The essential oil also possessed strong fumigant activity against $S$. zeamais and $T$. castaneum adults with $\mathrm{LC}_{50}$ values of 8.29 and $6.84 \mathrm{mg} / \mathrm{L}$, respectively (Table 2). The currently used grain fumigant, methyl bromide (MeBr) was reported to have fumigant activity $\left(24 \mathrm{~h}\right.$ ) against $S$. zeamais and $T$. castaneum adults with $\mathrm{LC}_{50}$ values of 0.67 and $1.75 \mathrm{mg} / \mathrm{L}$, respectively [33]. The essential oil was 12 times less toxic to the maize weevils and 4 times less toxic to the red flour beetles compared with the commercial fumigant MeBr. However, considering the currently used fumigants are synthetic insecticides, fumigant activity of the essential oil of M. exotica is quite promising and it shows potential to be developed as a possible natural fumigant for control of stored product insects.

In traditional Chinese medicine, M. exotica is used to treat many problems such as rheumatic fever, coughs, giddiness, hysteria and skin diseases [8]. It seems that this medicinal herb is quite safe to human consumption. However, no experimental data about the safety of this herb is available so far. In the previous studies, one of the main components of the essential oil ( $\alpha$-pinene) has been demonstrated contact and fumigant toxicity against several species of insects (cockroaches, head lice, cotton rootworm and stored product beetles and weevils) and mites [36-40]. However, no data on insecticidal activities of the other main components (spathulenol, caryophyllene oxide, $\alpha$-caryophyllene, bicyclogermacrene) of the essential oil was available. The isolation and identification of the bioactive 
compounds in the essential oil of M. exotica aerial parts are of utmost importance so that their potential application in controlling stored-product pests can be fully exploited.

\section{Experimental}

\subsection{Plant material}

Dried aerial parts (15 kg of leaves, young floriferous stems) of $M$. exotica were purchased from Puning Chinese Medicinal herbs Market (Guangdong 515300, China). The aerial parts were ground to a powder. The species was identified, and the voucher specimens (BNU-liuzhilong-2009-08-29-028) were deposited at the Herbarium (BNU) of College of Life Sciences, Beijing Normal University.

\subsection{Insects}

The maize weevil, S. zeamais and red flour beetle, T. castaneum were obtained from laboratory cultures maintained in the dark in incubators at $29-30{ }^{\circ} \mathrm{C}$ and $70-80 \%$ relative humidity. The red flour beetle, $T$. castaneum was reared on wheat flour mixed with yeast $(10: 1, \mathrm{w} / \mathrm{w})$ while $S$. zeamais was reared on whole wheat at $12-13 \%$ moisture content. Unsexed adult weevils/beetles used in all the experiments were about 2 weeks old.

\subsection{Essential oil distillation}

The ground powder of $M$. exotica was subjected to hydrodistillation using a modified Clevengertype apparatus for $6 \mathrm{~h}$ and extracted with $n$-hexane. Anhydrous sodium sulphate was used to remove water after extraction. Essential oil was stored in airtight containers in a refrigerator at $4{ }^{\circ} \mathrm{C}$. The oil yield of $M$. paniculata was $0.15 \% \mathrm{v} / \mathrm{w}$.

\subsection{Gas chromatography and mass spectrometry}

Gas chromatographic analysis was performed on an Agilent 6890N instrument equipped with a flame ionization detector and HP-5MS $(30 \mathrm{~m} \times 0.25 \mathrm{~mm} \times 0.25 \mu \mathrm{m})$ capillary column, while the essential oil components were identified on an Agilent Technologies $5973 \mathrm{~N}$ mass spectrometer. The GC settings were as follows: the initial oven temperature was held at $60{ }^{\circ} \mathrm{C}$ for $1 \mathrm{~min}$ and ramped at $10{ }^{\circ} \mathrm{C} \mathrm{min}{ }^{-1}$ to $180{ }^{\circ} \mathrm{C}$ for $1 \mathrm{~min}$, and then ramped at $20^{\circ} \mathrm{C} \mathrm{min}{ }^{-1}$ to $280{ }^{\circ} \mathrm{C}$ for $15 \mathrm{~min}$. The injector temperature was maintained at $270{ }^{\circ} \mathrm{C}$. The samples $(1 \mu \mathrm{L})$ were injected neat, with a split ratio of 1:10. The carrier gas was helium at flow rate of $1.0 \mathrm{~mL} \mathrm{~min}{ }^{-1}$. Spectra were scanned from 20 to $550 \mathrm{~m} / \mathrm{z}$ at 2 scans $\mathrm{s}^{-1}$. Most constituents were identified by gas chromatography by comparison of their retention indices with those of the literature or with those of authentic compounds available in our laboratories. The retention indices were determined in relation to a homologous series of $n$-alkanes $\left(\mathrm{C}_{8}-\mathrm{C}_{24}\right)$ under the same operating conditions. Further identification was made by comparison of their mass spectra on both columns with those stored in NIST 05 and Wiley 275 libraries or with mass spectra from literature [34]. Component relative percentages were calculated based on GC peak areas without using correction factors. 


\subsection{Fumigant toxicity}

The fumigant activity of the essential oil against $S$. zeamais and $T$. castaneum adults was tested as described by Liu and Ho [1]. A serial dilution of the essential oil (six concentrations) was prepared in $n$-hexane. A Whatman filter paper (diameter $2.0 \mathrm{~cm}$ ) were each impregnated with $20 \mu \mathrm{L}$ dilution, and then placed on the underside of the screw cap of a glass vial (diameter $2.5 \mathrm{~cm}$, height $5.5 \mathrm{~cm}$, volume $25 \mathrm{~mL}$ ). The solvent was allowed to evaporate for $30 \mathrm{~s}$ before the cap was placed tightly on the glass vial, each of which contained 10 insects inside to form a sealed chamber. Preliminary experiments demonstrated that $30 \mathrm{~s}$ was sufficient for the evaporation of solvents. $n$ Hexane was used as a control. Five replicates were carried out for all treatments and controls, and they were incubated for $24 \mathrm{~h}$. The insects were then transferred to clean vials with some culture media and returned to the incubator and observed daily for determination of end-point mortality, which was reached after one week. The experiments were repeated in three times. The $\mathrm{LC}_{50}$ values were calculated by using Probit analysis [35].

\subsection{Contact toxicity}

The contact toxicity of the essential oil against $S$. zeamais and T. castaneum adults was measured as described by Liu and Ho [1]. A serial dilution of the essential oil (five concentrations) was prepared in $n$-hexane. Aliquots of $0.5 \mu \mathrm{L}$ of the dilutions were applied topically to the dorsal thorax of the insects. Controls were determined using $n$-hexane. Both treated and control insects were then transferred to glass vials (10 insects/vial) with culture media and kept in incubators. Mortality of insects was observed daily until end-point mortality was reached one week after treatment. The experiments were repeated in three times. The $\mathrm{LD}_{50}$ values were calculated by using Probit analysis [35]. Pyrethrum extract (25\% pyrethrine I and pyrethrine II) was purchased from Fluka Chemika GmbH and used as a positive control.

\section{Conclusions}

Based on mass screening, essential oil of $M$. exotica was examined for their insecticidal activity against the two grain storage insects. The essential oil possessed strong fumigant toxicity against adults of the two grain storage insects, although it was 10 times and 4 times less toxic to the maize weevil and red flour beetle, respectively compared to commercial fumigant $\mathrm{MeBr}$. The essential oil also showed contact toxicity against adults of the two grain storage insects. These findings, considered together, suggest that the essential oil shows potential for development as a natural fumigant for stored products.

\section{Acknowledgements}

This work was funded by the Hi-Tech Research and Development of China 2006AA10A209. The authors thank Q.R. Liu, College of Life Sciences, Beijing Normal University, Beijing 100875, China, for identification of the medicinal herbs. 


\section{References}

1. Liu, Z.L.; Ho, S.H. Bioactivity of the essential oil extracted from Evodia rutaecarpa Hook f. et Thomas against the grain storage insects, Sitophilus zeamais Motsch. and Tribolium castaneum (Herbst). J. Stored Prod. Res. 1999, 35, 317-328.

2. Isman, M.B. Botanical insecticides, deterrents, and repellents in modern agriculture and an increasingly regulated world. Ann. Rev. Entomol. 2006, 51, 45-66.

3. Zettler, J.L.; Arthur, F.H. Chemical control of stored product insects with fumigants and residual treatments. Crop Prot. 2000, 19, 577-582.

4. Isman, M.B. Perspective botanical insecticides: For richer, for poorer. Pest Manag. Sci. 2008, 64, $8-11$.

5. Rajendran, S.; Srianjini, V. Plant products as fumigants for stored-product insects control. $J$. Stored Prod. Res. 2008, 44, 126-135.

6. Isman, M.B. Plant essential oils for pest and disease management. Crop Prot. 2000, 19, 603-608.

7. Zhang, D.X.; Hartley, T.G.; Mabberley, D.J. Flora of China. http://www.flora.ac.cn/cecontent.aspx?TaxonId=220008880. (accessed online in 2003).

8. Jiangsu New Medical College. Dictionary of Chinese Herbal Medicine; Shanghai Science \& Technology Press: Shanghai, China, 1977; pp. 44-47.

9. Pery, L.M. Medicinal Plants of East and Southeast Asia: Attributed Properties and Uses; MIT Press: Cambridge, MA, USA, 1980; p. 367.

10. Wang, X.Z; Ma, Y.D; Li, X.W.; Gui, M.Y. Ma, S.C.; Jin, Y.R. Structural elucidation of methoxyflavone compounds extracted from the leaves of Murraya exotica L. by NMR spectroscopy. Chin. J. Magn. Reson. 2007, 24, 341-346, in Chinese.

11. Negi, N.; Ochi, A.; Kurosawa, M.; Ushijima, K.; Kitaguchi, Y.; Kusakabe, E.; Okasho, F.; Kimachi, T.; Teshima, N.; Ju-ichi, M.; Abou-Douh, A.M.; Ito, C.; Furukawa, H. Two new dimeric coumarins isolated from Murraya exotica. Chem. Pharm. Bull. 2005, 53, 1180-1182.

12. Desoky, E.K. Occurrence of 24-alkyl-9,19-cyclolanost-25-enes in Murraya exotica L. Indian J. Chem. 1996, 35B, 1113-1115.

13. Desoky, E.K. Phytosterols from Murraya exotica. Phytochemistry 1995, 40, 1769-1772.

14. Desoky, E.K. Long-chain polyprenyl acetates in Murraya exotica. Phytochemistry 1995, 39, 1383-1385.

15. Desoky, E.K. A new flavonoidal coumarin from Murraya exotica L. Indian J. Chem. 1995, 34B, 747-749.

16. Ito, C.; Furukawa, H. Two new coumarins from Murraya plants. Chem. Pharm. Bull. 1989, 37, 819-820.

17. Ito, C.; Furukawa, H. Constituents of Murraya exotica L. Structure elucidation of new coumarins. Chem. Pharm. Bull. 1987, 35, 4277-4285.

18. Ahmad, Z.A.; Tripathi, G.S.; Begum, S. Sitosterol- $\beta$-D-galactoside from Murraya exotica. Planta Med. 1987, 53, 579.

19. Barik, B.R.; Kundu, A.B. A cinnamic acid derivative and a coumarin from Murraya exotica. Phytochemistry 1987, 26, 3319-3321. 
20. Kong, Y.C.; Ng, K.H.; But, P.P.H.; Cheng, K.F.; Waterman, P.G. Aurantiamide acetate in the stem bark of Murraya exotica. Planta Med. 1987, 53, 393.

21. Ito, C.; Furukawa, H. Three new coumarins from Murraya exotica. Heterocycles 1987, 26, 1731-17344.

22. Kong, Y.C.; Ng, K.H.; But, P.P.H.; Li, Q.; Yu, S.X; Zhang, H.T.; Cheng, K.F.; Soejarto, D.D.; Kan, W.S.; Waterman, P.G. Sources of the anti-implantation alkaloid yuehchukene in the genus Murraya. J. Ethnopharmacol. 1986, 15, 195-200.

23. Barik, B.R.; Dey, A.K.; Chatterjee, A. Murrayatin, a coumarin from Murraya exotica. Phytochemistry 1983, 22, 2273-2275.

24. Barik, B.R.; Dey, A.K.; Das, P.C.; Chatterjee, A.; Shoolery, J.N. Coumarins of Murraya exotica. Absolute configuration of auraptenol. Phytochemistry 1983, 22, 792-794.

25. Ganguly, S.N.; Sarkar, A. Exozoline, a new carbazole alkaloid from the leaves of Murraya exotica. Phytochemistry 1978, 17, 1816-1817.

26. Jiang, P.C.; Zhou, J.; Cao, B.; Wei, G.N.; He, K.J.; Liu, B.M. Study on the volatile of Murraya exotica. J. Chin. Med. Mater. 2009, 32, 124-1227 (In Chinese with English abstract).

27. Rout, P.K.; Rao, Y.R.; Sree, A.; Naik, S.N. Composition of essential oil, concrete, absolute, wax and headspace volatiles of Murraya paniculata (Linn.) Jack flowers. Flavour Frag. J. 2007, 22, 352-357.

28. Raina, V.K.; Verma, S.C.; Dhawan, S.; Khan, M.; Ramesh, S.; Singh, S.C.; Yadav, A.; Srivastava, S.K. Essential oil composition of Murraya exotica from the plains of northern India. Flavour Frag. J. 2006, 21, 140-142.

29. Pino, J.A.; Marbot, R.; Fuentes, V. Aromatic plants from western Cuba. VI. Composition of the leaf oils of Murraya exotica L., Amyris balsamifera L., Severinia buxifolia (Poir.) Ten. and Triphasia trifolia (Burm. f.) P. Wilson. J. Essent. Oil Res. 2006, 18, 24-28.

30. Olawore, N.O.; Ogunwander, I.A.; Ekundayo, O.; Adeleke, K.A. Chemical composition of the leaf and fruit essential oils of Murraya paniculata (L.) Jack. (Syn. Murraya exotica Linn.). Flavour Frag. J. 2005, 20, 54-56.

31. El-Sakhawy, F.S.; El-Tantawy, M.E.; Ross, S.A.; El-Sohly, M.A. Composition and antimicrobial activity of the essential oil of Murraya exotica L. Flavour Frag. J. 1998, 13, 59-62.

32. Wang, L.Y.; Lu, Y.Q.; Luo, Y.P. Antifeeding activities of 45 south herbs extracts against Spodptera litura Fabriciu. Hubei Agric. Sci. 2009, 48, 628-630 (In Chinese with English abstract).

33. Zhou, Q.; Liang, G.W.; Zeng, L. Study on antifeedant effect of plant extracts on Myzus persicae (Sulzer) and Lipaphis erysimi (Kaltenbach). Nat. Prod. Res. Dev. 2004, 16, 521-524 (In Chinese with English abstract).

34. Adams, R.P. Identification of Essential Oil Components by Gas Chromatography/Quadrupole Mass Spectroscopy; Allured: Carol Stream, IL, USA, 2001.

35. Sakuma, M. Probit analysis of preference data. Appl. Entomol. Zool. 1998, 33, 339-347.

36. Lee, S.Y.; Tsao, R.; Peterson, C.; Coats, J.R. Insecticidal activity of monoterpenoids to western corn rootworm (Coleoptera: Chrysomelidae), twospotted spider mite (Acari: Tetranychidae), and house fly (Diptera: Muscidae). J. Econ. Entomol. 1997, 90, 883-892. 
37. Ngoh, S.P.; Choo, L.E.W.; Pang, F.Y.; Huang, Y.; Kini, M.R.; Ho, S.H. Insecticidal and repellent properties of nine volatile constituents of essential oils against the American cockroach, Periplaneta americana (L.). Pestic. Sci. 1998, 54, 261-268.

38. Park, I.K.; Lee, S.G.; Choi, D.H.; Park, J.D.; Ahn, Y.J. Insecticidal activities of constituents identified in the essential oil from leaves of Chamaecyparis obtusa against Callosobruchus chinensis (L.) and Sitophilus oryzae (L.). J. Stored Prod. Res. 2003, 39, 375-384.

39. Jang, Y.S.; Yang, Y.C.; Choi, D.S.; Ahn, Y.J. Vapor phase toxicity of marjoram oil compounds and their related monoterpenoids to Blattella germanica (Orthoptera: Blattellidae). J. Agric. Food Chem. 2005, 53, 7892-7898.

40. Yang, Y.C.; Lee, S.H.; Clark, J.M.; Ahn, Y.J. Ovicidal and adulticidal activities of Origanum majorana essential oil constituents against insecticide-susceptible and pyrethroid/malathionresistant Pediculus humanus capitis (Anoplura: Pediculidae). J. Agric. Food Chem. 2009, 57, 2282-2287.

Sample Availability: Sample of essential oil are available from the authors.

(C) 2010 by the authors; licensee MDPI, Basel, Switzerland. This article is an Open Access article distributed under the terms and conditions of the Creative Commons Attribution license (http://creativecommons.org/licenses/by/3.0/). 